\title{
Biodegradable Capability of the Indigenous Micrococcus sp. Oil Degrading Bacteria Isolated from Oil Contaminated Soil, Motor Workshop Area of Bahror, Alwar, Rajasthan, India.
}

\author{
Mohan Lal Kuri, Vidya Kumari, Shikha Roy
}

\begin{abstract}
Crude oil contamination is one of the important issue in the current environment pollution. Physical, chemical and biological methods are applied for bioremediation. Use of microorganisms is one of the most popular methods among them. In this experiment, soil samples were collected from the different motor workshop areas to isolate potential microbes capable of crude oil degradation. Isolation of the crude oil degrading bacteria was followed by enriching the microorganisms by providing suitable growth conditions. The microorganisms those were capable of degrading the crude oil were identified as Bacillus spp., Pseudoxanthomonas spp., Phenylobacterium spp. and Micrococcus spp. by morphological and biological methods. Among them, biodegradation capability of Micrococcus sp. was studied at different oil concentrations.
\end{abstract}

Key Points: Crude Oil Degradation, Micrococcus sp., Indigenous, Contaminated Soil.

\section{INTRODUCTION}

Nowadays deliberate use of petroleum hydrocarbon products, such as diesel and engine oil increases the chance of soil pollution and gradually it is proving itself as a major environmental problem ${ }^{[1]}$. The spillage also has severe healthrelated impacts on human and aquatic animals. It may cause severe risks to the workers associated with the cleaning up of oil spillage areas when exposed to oil fumes, volatile organic compounds ${ }^{[2,3,4]}$, polycyclic aromatic hydrocarbons $(\mathrm{PAHs})^{[5,6]}$, particulate matter from controlled burns, and heavy metals.

Environmental pollution arising from petroleum leakages in storage tanks, spillage during transportation of petroleum products, deliberate discharge of petroleum products and various industrial processes is hazardous to soil and water ecosystems ${ }^{[7]}$. This also results in huge disturbances of the abiotic and biotic components of the ecosystem ${ }^{[8]}$. Most of the study has shown Pseudomonas aeruginosa, Pseudomonas putida, Acinetobacter spp., Flavobacterium spp., Yokenellaspp., Alcaligenes spp., Roseomonasspp.,Sphingobacteriumspp., Capnocytophagaspp., Moraxella spp., Corynebacterium spp., Streptococcus spp., Providencia spp., etc. as common hydrocarbon degraders $\left.{ }^{[9,} 10,11\right]$. Biodegradation of complex hydrocarbons, naphthalene and pyrene with the help of Bacillus spp., has been shown in many literatures and the degradation was found to be ranging from 20 to $60 \%{ }^{[12,13,14]}$.

Revised Manuscript Received on October 06, 2020.

* Correspondence Author

Mohan Lal Kuri*, Department of Botany, University of Rajasthan, Jaipur, India. E-mail: botgeog.mlk@gmail.com

Vidya Kumari, Department of Botany, University of Rajasthan, Jaipur, India. India.

Shikha Roy, Department of Botany, University of Rajasthan, Jaipur,

(C) The Authors. Published by Blue Eyes Intelligence Engineering and Sciences Publication (BEIESP). This is an open access article under the CC BY-NC-ND license (http://creativecommons.org/licenses/by-nc-nd/4.0/)
Biological and non-biological approaches are being used for remediation of oil pollution. Bioremediation is one of the principle strategies for remediation, wherein the pollution can be removed by use of microorganism or by any biological process that uses microorganisms or their enzymes to return the environment altered by contaminants to its original condition ${ }^{[15]}$.The ability of many microorganisms in order to biodegradation of hydrocarbons has been studied ${ }^{[16,17,18]}$.These methods are less expensive and do not introduce additional chemicals to the environment.

\section{METHOD AND MATERIAL}

Survey and Sampling sites: A survey was conducted time to time beside rainy season to explore the different soil sample during the year.Thepresent studywas aimed to study the hydrocarbon contaminated sites of Bahror, Alwar for their biodegradation of petroleum hydrocarbons. Soil sample was collected from different motor workshop areas of Bahror region, Alwar, Rajasthan, India. The samples were collected in sterilized sample containers. The soil samples were stored at $4^{\circ} \mathrm{C}$ and immediately transferred to the laboratory for further analysis.

Isolation of Microorganisms: Bacterial Isolation and screening: Petroleum hydrocarbon degrading bacteria were isolated from the contaminated soil by using serial dilution method.For inoculation thin layer Bushnell Hash Agar (BHA)medium plates were prepared. $1 \mathrm{ml}$ of $2 \mathrm{~T}$ oil (obtained from Bharat Petroleum Depot, Sitapura and Jaipur) was spread up over the surface of the medium. It was done in sterile conditions.

The inoculated Petri-plates were incubated for 2-5 days at $37^{\circ} \mathrm{C}$ temperature. The colonies developed were picked up carefully with inoculation loop and transferred to sterile fresh media. The bacterial cultures were sub cultured at an interval of 6 months, to maintain the cultures.

Cultural characteristics and Gram staining of the bacterial isolate: When bacterial isolate grown on Bushnell Haas Agar Media (BHA) containing 2T oil as sole source of energy, microorganisms show difference in the appearance of their growth on the basis of shape, margin, elevation and color. These differences, called cultural or colony characteristics.

Published By:

Blue Eyes Intelligence Engineering

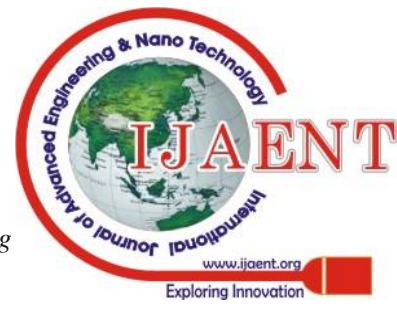


Gram staining technique is useful staining for identifying and classifying bacteria. The stain allows us to classify bacteria as either gram positive or gram negative.

The most important determining factor in the procedure is that bacteria differ in their rate of decolorization. Those that decolorize easily are referred to as gram negative, whereas those that decolorize slowly and retain the primary stain are called gram positive.

Biochemical characteristics of the Bacterial isolate: The various biochemical tests were enable to characterization and identification up to genus level.

\section{QUANTITATIVE ANALYSIS}

A. Bacterial degradation of the petroleum oil (2T Engine oil (Fig.5.1a)):

The Luria Bertani (LB) Broth (pH 7.5) media ${ }^{[19]}$ was prepared and then the bacterial culture was inoculated into the LB Broth media and incubated at $37^{\circ} \mathrm{C}$ for 48 hours. Subsequently the Mineral Salt (MS) Medium having pH 5.6 \pm 2 (Fig.5.1b) was prepared and then 1\% 2T engine oil was inoculated into the MS Medium. This 1\% 2T engine oil containing MS medium was then inoculated with isolated bacterial cultures from LB broth medium. Then the Gravimetric analysis was conducted on day 0, day 7, day 10 and day 14 . For further extension of the experiment, $4 \%$ and $10 \% 2 \mathrm{~T}$ engine oil was inoculated onto the MS medium.

\section{GRAVIMETRIC ANALYSIS}

Taking 25ml culture from MS Media in a clean flask, $1 \% 1 \mathrm{~N} \mathrm{HCl}$ was added into each flask. After which, this 25 $\mathrm{ml}$ culture was transferred to the separating funnel and to which $25 \mathrm{ml}$ Petroleum ether and Acetone (in 1:1 ratio) added (Fig.5.2) and mixed properly. Then added $1 \mathrm{ml}$ Acetone and let the separating funnel remain still for 15-20 minutes (Fig.5.3). After 15-20 minutes, different layers (3 layers) were observed (Fig.5.4). Then from the separating funnel, the $1^{\text {st }}$ and $2^{\text {nd }}$ layers were discarded (Fig. 5.5) and the $3^{\text {rd }}$ layer was collected in the clean pre-weighed (initial weight) beaker (Fig. 5.6). This beaker was heated in the water bath at $100^{\circ} \mathrm{C}$ for $10-15$ minutes for evaporation (Fig. 5.7). Once the evaporation is complete, the beaker was cleaned from outside properly to remove any water on the outer side and again the weight of the beaker (final weight) was taken. The amount of oil left in the beaker after evaporation was calculated as follows:

Amount of oil left $=$ Final weight of beaker - Initial weight of beaker

Percent Degradation was calculated by the following formula:

Degradation $=($ Initial weight - Final weight $) /$ Initial weight $\times 100$

\section{RESULTS AND DISCUSSION}

Among the various microorganisms obtained from contaminated soil of different motor workshop areas on the nutrient agar plates, selected colonies were able to grow on Bushnell Haas medium crude oil degradation. Micrococcus $s p$. might be resistance of crude oil presence and hence survived in such environment. The growths of colonies of these microbes are depended on their capability of crude of degradation. Higher degradation librates more carbons in the media, which will be readily available to microbes for their growth and reproduction. Hence, based on the colony growth it was found that these four microbes are potential crude oil degraders.

Micrococcus sp. showedfluctuation of percentage oil degradation at various oil concentrations (At 1\%, 4\% and $10 \%$ ). Micrococcus sp. shows maximum upto $69 \%$ petroleum oil degradation at $1 \%$ oil concentration in $0-14$ days of intervals. At $4 \%$ oil concentration in $0-14$ day's interval, it showed17.90\%, $60.75 \%$ and $61.84 \%$ oil degradation.Minimum percentage of oil degradation was showed at $10 \%$ oil concentration upto $12.77 \%$.

Conclusively it showed slowly but gradually oil degradation at long term.

Table 1.1: Gram's reaction and cell morphology of Micrococcus sp.

\begin{tabular}{|c|c|c|c|c|}
\hline S. No. & Sample Code & Isolation No. & Cell Morphology & Gram's Reaction \\
\hline 2 & B & BS-B1 & Coccoid & Positive \\
\hline
\end{tabular}

Table 1.2: Percent degradation of oil (At 1\% oil concentration)

\begin{tabular}{|c|c|c|c|c|}
\hline Bacterial Isolate & \multirow{2}{*}{ Sample code } & \multicolumn{3}{|c|}{ Percent degradation (\%) } \\
\cline { 3 - 5 } & & 0 to 7 Day & 0 to 10 Day & 0 to 14 Day \\
\hline Micrococcus sp. & BS-B1 & 4.53686 & 43.8563 & 68.242 \\
\hline
\end{tabular}

Table 1.3: Percentage of oil degradation (At 4\% 2T Engine oil)

\begin{tabular}{|c|c|r|r|c|}
\hline \multirow{2}{*}{ Bacterial Isolate } & \multirow{2}{*}{ Sample code } & \multicolumn{3}{|c|}{ Percent degradation } \\
\cline { 3 - 5 } & & Day0 to 7 & Day0 to 10 & \multicolumn{1}{c|}{ Day0 to 14 } \\
\hline Micrococcus sp. & BS-B1 & 17.9039 & 60.7533 & 61.845 \\
\hline
\end{tabular}


Table 1.4 Percentage of oil degradation: At 10\% 2T Engine oil

\begin{tabular}{|c|c|c|c|c|}
\hline \multirow{2}{*}{ Bacterial Isolate } & \multirow{2}{*}{ Sample Code } & \multicolumn{3}{|c|}{ Percent degradation } \\
\cline { 3 - 5 } & & Day0 to 7 & Day0 to 10 & Day0 to 14 \\
\hline Micrococcus sp. & BS-B1 & 1.20 & 7.58 & 12.77 \\
\hline
\end{tabular}

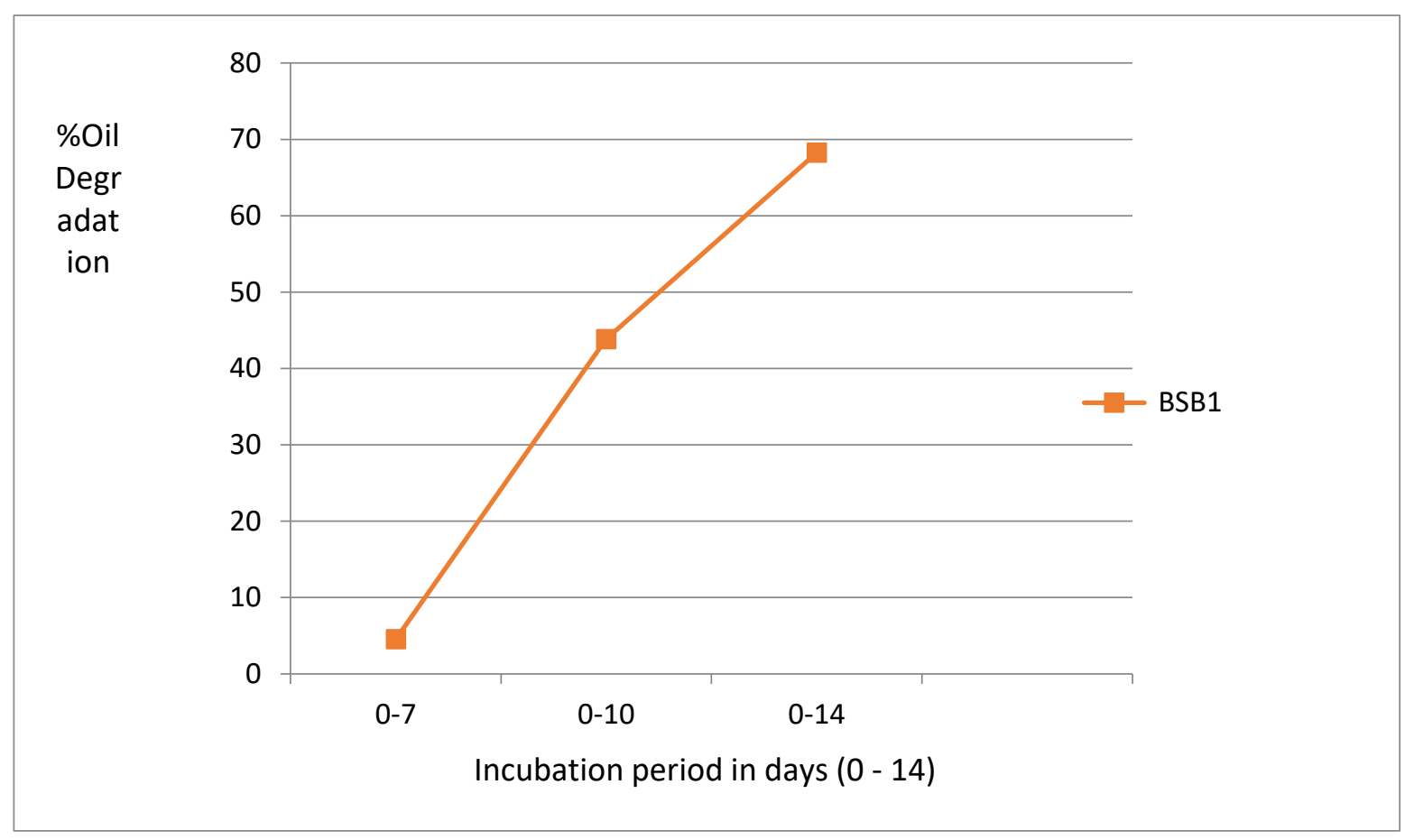

Figure: A. Percent degradation of oil by the BS-B1= Micrococcus sp. (At 1\% 2T oil concen.)

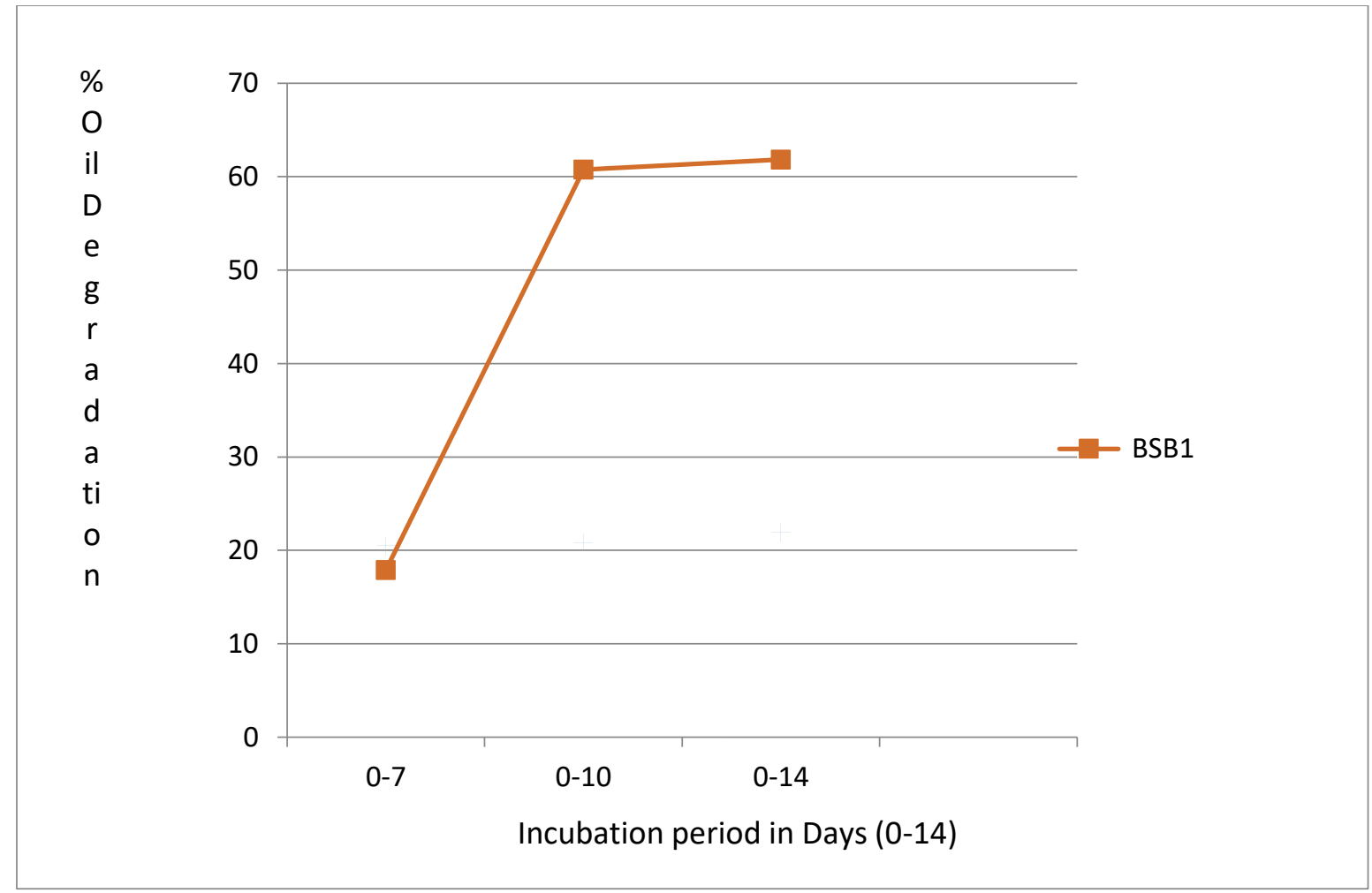

Figure: B. Percent degradation of oil by the BS-B1=Micrococcus sp. (At 4\% Oil Concen.) 
Biodegradable Capability of the Indigenous Micrococcus sp. Oil Degrading Bacteria Isolated from Oil Contaminated Soil, Motor Workshop Area of Bahror, Alwar, Rajasthan, India.

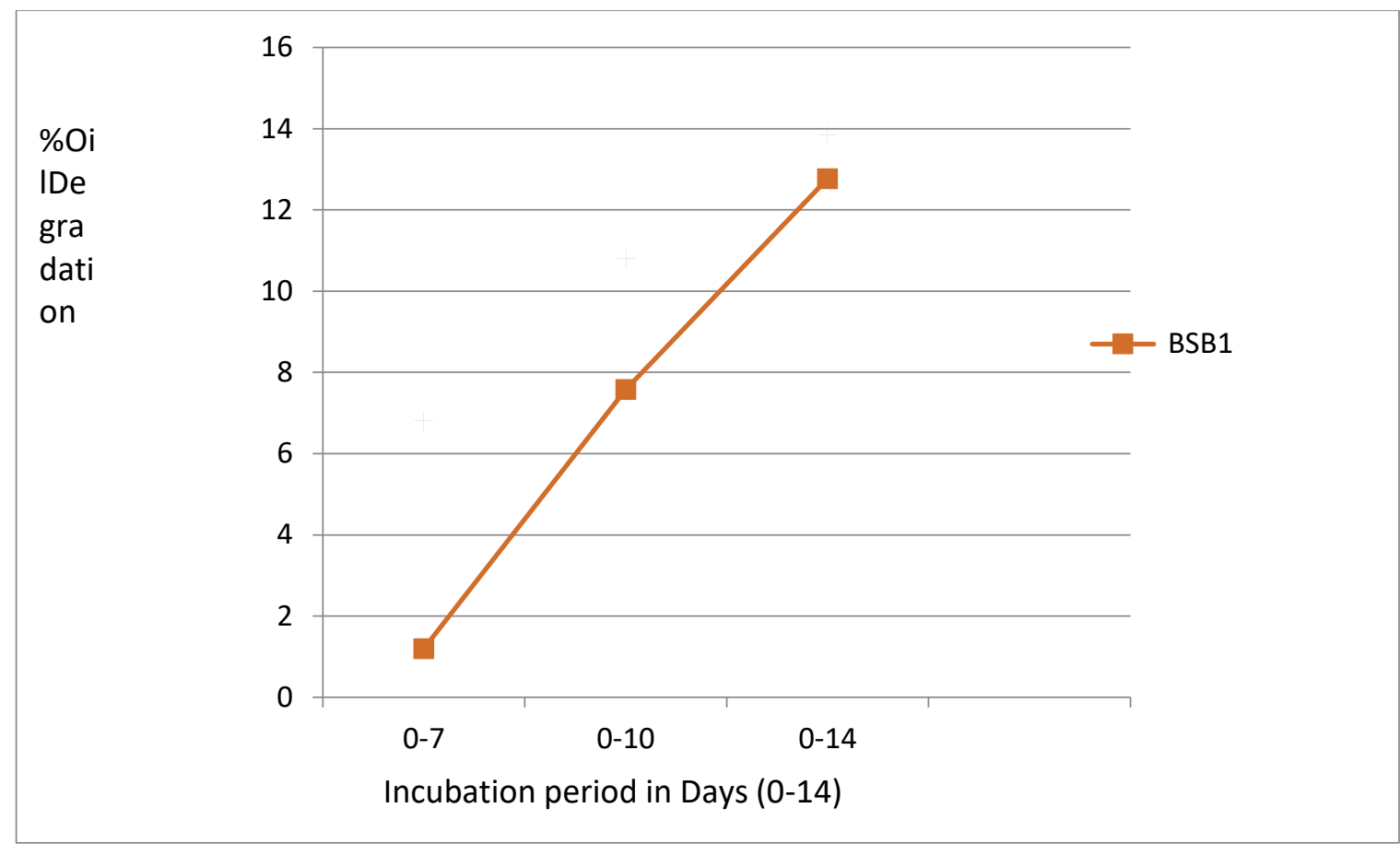

Figure: C. Percent degradation of oil by the BS-B1=Micrococcus sp. (At 10\% oil Concen.)

\section{REFERENCES}

1. N. R. C. Oil in the Sea: Inputs, Fates and Effects. National Academy Press, Washington, DC, USA, ISBN13: 9780309078351, 1985;pp. 607.

2. Q. D. Bach, S. J. Kim, S.C. Choi, Y. S. Oh. Enhancing the intrinsic bioremediation of PAH-contaminated anoxic estuarine sediments with biostimulatingagents. J. Microbiol., 2005; pp. 319-324.

3. J. F. Biddle, J. S. Lipp, M. A. Lever, K. G. Lloyd, K. B. Sørensen, R. Andersonc, H. F. Fredricks, M.Elvert, T. J. Kelly, D. P. Schrag, M. L. Sogin, J. E. Brenchley, A. Teske, C. H. House, K. U. Hinrichs. Heterotrophic Archaea dominate sedimentary subsurface ecosystems off Peru. Proc. Natl. Acad. Sci. USA. 2006; pp. 3846-3851.

4. B. J. Campbell, S. C. Cary. Characterization of a novel Spirochete associated with the hydrothermal vent polychaete annelid, Alvinella pompejana. Appl. Environ. Microbiol.2001;pp. 110- 117.

5. B. V.Chang, L. C. Shiung, S. Y. Yuan. Anaerobic biodegradation of polycyclic aromatic hydrocarbon in soil. Chemosphere. 2002;pp. 717724.

6. W. Chang, Y. Um, B. Hoffman, T. R. P. Holoman. Molecular characterization of polycyclic aromatic hydrocarbon (PAH)degrading methanogenic communities. Biotechnol. Prog. 2005;pp.682-688.

7. S. J. Geetha, J. J. Sanket, K. Shailesh. Isolation and characterization of hydrocarbon degrading bacterial isolate from oil contaminated sites, APCBEE Procedia. 2013; pp. 237 - 241.

8. A. I. Okoh. Biodegradation alternative in the cleanup of petroleum hydrocarbon pollutants.Biotechnology and Molecular Biology Review. 2006;pp. 38-50.

9. T. Mandri, J. Lin. Isolation and characterization of engine oil degrading indigenous microrganisms in Kwazulu-Natal, South Africa. Afr. J. Biotechnol., 2007; pp. 23-27.

10. A. A. Juwarkar. Microbe-assisted phytoremediation for restoration of biodiversity of degraded lands: A sustainable solution. Proc. Natl. Acad. Sci. India, 2012;pp. 313-318.

11. D. S. Etkin. Oil spills from production and exploration activities. Oil Spill Intelligence Report, 1998.

12. F. M. Ghazali, R. N. Z. A. Rahman, A. B. Salleh, M. Basri. Biodegradation of hydrocarbons in soil by microbial consortium. Int Biodet. Biodeg., 2004;pp. 61 -67.

13. K. Das, A. K. Mukherjee. Crude petroleum-oil biodegradation efficiency of Bacillus subtilis and Pseudomonas aeruginosa strains isolated from a petroleumoil contaminated soil from North-East India. Bioresour. Technol.,2007; pp. 1339 -1345.

14. M. Bujang, N. A. Ibrahim, E. A. Rak. Biodegradation of oily wastewater by pure culture of Bacillus cereus. ARPN J. Agric. Biol. Sci., 2013;pp.108 -115.
15. O. A. Olu-Arotiowa, M. O. Aremu, A. O. Alade. Ex-situ bioremediation of diesel polluted waste water in trophical hot climate. Asia J. Info. Technol., 2007;pp. 961-963.

16. J.Liangli, B. Hungchen. Surfactant mediated biodegradation of polycyclic aromatic hydrocarbons. Materials,2009;pp. 76-94.

17. M. R. Sarikhani, M. Ebrahimi, A. R. Fallah. Comparison of hydrocarbon-degradation by isolates of Pseudomonas fluorescens Chao, P. Putida and Pantoea agglomerans P5 in presence of gas oil, toluene and phenanthrene. 4th International Conference of Environmental Industrial and Applied Microbiology, 2011.

18. M. Ebrahimi, R. Fallah, M. R. Sarikhani, M. T. Taheri. Assessment of biodegradation efficiency of some isolated bacteria from oil contaminated sites in solid and liquid media containing oilcompounds. Int. Res. J. Appl. Basic Sci.,pp. 138 - 147.

19. A. Mittal, P. Singh. Isolation of hydrocarbon degrading bacteria from soils contaminated with crude oil spills. 2009; pp. 760-765.

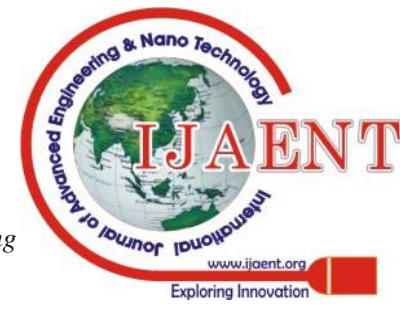

